\title{
Central Diabetes Insipidus Diagnosed After Gynecologic Surgery: A Case Report
}

\author{
Nobuhiro Akuzawa ${ }^{\mathrm{a}, \mathrm{c}}$, Naoyuki Harada ${ }^{\mathrm{a}}$, Noriko Hasegawa ${ }^{\mathrm{a}}$, Hidenori Seki ${ }^{\mathrm{a}}$, Yuko Oku ${ }^{\mathrm{a}}$, \\ Masayuki Totsuka ${ }^{a}$, Takashi Hatori ${ }^{a}$, Atsushi Murakami ${ }^{a}$, Kunihiko Imai ${ }^{a}$, \\ Yonosuke Kitahara ${ }^{a}$, Masahiko Tashiro ${ }^{a}$, Masahiko Kurabayashi ${ }^{\mathrm{b}}$
}

\begin{abstract}
A 41-year-old woman with non-alcoholic fatty liver disease and complex endometrial hyperplasia with atypia was admitted to our hospital to undergo hysterectomy. Her weight was $107 \mathrm{~kg}$, having doubled after delivery of her second child. After a routine hysterectomy, unexpected polyuria was observed. Investigation revealed a relatively low plasma vasopressin concentration, and absence of hyperintense signals in the region of the posterior lobe of the pituitary gland on T1-weighted magnetic resonance imaging, suggesting partial central diabetes insipidus. It was concluded that excessive intake of sweetened carbonated beverages due to thirst caused by diabetes insipidus had contributed to her obesity.
\end{abstract}

Keywords: Central diabetes insipidus; Magnetic resonance imaging; Obesity; Polyuria; Vasopressin

\section{Introduction}

Central diabetes insipidus (CDI) is caused by a decreased arginine vasopressin level, and is characterized by polyuria and polydipsia. This condition occurs equally in both sexes and affects all age groups, with the most frequent age of onset being between 10 and 20 years [1]. Patients are classified as having partial CDI or complete CDI based on the findings of a water deprivation test [2]. Complete CDI is less common than partial CDI [1]. In partial CDI, moderately excessive diuresis may be the only symptom, and plasma osmo-

\footnotetext{
Manuscript accepted for publication January 22, 2013

${ }^{a}$ Department of Internal Medicine, Social Insurance Gunma Chuo General Hospital, 1-7-13 Koun-cho, Maebashi, Gunma 371-0025, Japan

${ }^{\mathrm{b}}$ Department of Medicine and Biological Science, Gunma University Graduate School of Medicine, 3-39-22 Showa-machi, Maebashi, Gunma 371-8511, Japan

${ }^{\mathrm{c} C}$ Correponding author: Nobuhiro Akuzawa, Social Insurance Gunma Chuo General Hospital, 1-7-13 Koun-cho, Maebashi, Gunma 371-

0025, Japan. Email: akuzawa_nobuhiro@yahoo.co.jp
}

doi: http://dx.doi.org/10.4021/jem147e larity usually only slightly exceeds $290 \mathrm{mOsm} / \mathrm{kg}$ (normal range: 280 - $295 \mathrm{mOsm} / \mathrm{kg}$ ) [3].

CDI may result from any condition that impairs the synthesis, transport or release of arginine vasopressin. Known causes of secondary CDI include tumors, infections, trauma, and other conditions such as histiocytosis and vascular lesions $[1,2]$. Idiopathic CDI is caused by selective hypofunction of the hypothalamic-neurohypophysial system, and accounts for $20-50 \%$ of all cases of CDI [4]. Patients often experience weight loss induced by excessive loss of free water [5].

Here, we describe a rare case of weight gain associated with partial CDI that was initially misdiagnosed as simple obesity. Observation of polyuria and hypernatremia after gynecologic surgery provided an opportunity to make the correct diagnosis. A detailed medical history revealed that excessive intake of sweetened carbonated beverages due to thirst caused by CDI may have contributed to her marked weight gain.

\section{Case Report}

A 41-year-old woman was admitted to the Department of Obstetrics and Gynecology at our hospital to undergo hysterectomy for complex endometrial hyperplasia with atypia. She had been diagnosed with simple endometrial hyperplasia 2 years previously, and surgical treatment was recommended because of progression of cellular atypia and endometrial thickening. Prior to surgery, she underwent medical review to evaluate the risks of general anesthesia in the presence of her impaired liver function.

When she first visited our department, she reported no thirst, polyuria or polydipsia. She had no other significant medical history or family history, was not taking any medications and denied alcohol intake. Her height was $153 \mathrm{~cm}$ and weight was $107 \mathrm{~kg}$. Her body mass index was $45.7 \mathrm{~kg} /$ $\mathrm{m} 2$, indicating severe obesity. Her weight had been $58 \mathrm{~kg}$ at the time of the birth of her second child at age 35, and had increased by about $10 \mathrm{~kg}$ per year since then. Previous testing at another general hospital had shown normal plasma concentrations of thyroid and adrenocortical hormones. Her 
Table 1. Laboratory Test Results at 1 Week Before Admission

\begin{tabular}{|c|c|}
\hline \multicolumn{2}{|l|}{ Hematology } \\
\hline WBC & $5,600 / \mathrm{mm}^{3}$ \\
\hline $\mathrm{RBC}$ & $528 \times 10^{4} / \mathrm{mm}^{3}$ \\
\hline Hemoglobin & $14.2 \mathrm{~g} / \mathrm{dL}$ \\
\hline Hematocrit & $44.9 \%$ \\
\hline Platelet & $16.3 \times 10^{4} / \mathrm{mm}^{3}$ \\
\hline \multicolumn{2}{|l|}{ Blood Coagulation Test } \\
\hline International Normalized Ratio of Prothrombin Time & 1.05 \\
\hline \multicolumn{2}{|l|}{ Blood Chemistry } \\
\hline Total Protein & $7.7 \mathrm{~g} / \mathrm{dL}$ \\
\hline Albumin & $4.1 \mathrm{~g} / \mathrm{dL}$ \\
\hline $\mathrm{AST}^{*}$ & $49 \mathrm{IU} / \mathrm{L}$ \\
\hline ALT $^{*}$ & $57 \mathrm{IU} / \mathrm{L}$ \\
\hline $\mathrm{LDH}$ & $223 \mathrm{IU} / \mathrm{L}$ \\
\hline ALP* & $321 \mathrm{IU} / \mathrm{L}$ \\
\hline gGTP* & $73 \mathrm{IU} / \mathrm{L}$ \\
\hline Total Birirubin & $0.6 \mathrm{mg} / \mathrm{dL}$ \\
\hline CPK & $48 \mathrm{IU} / \mathrm{L}$ \\
\hline BUN & $5.8 \mathrm{mg} / \mathrm{dL}$ \\
\hline Cre & $0.52 \mathrm{mg} / \mathrm{dL}$ \\
\hline $\mathrm{Na}$ & $141 \mathrm{mEq} / \mathrm{L}$ \\
\hline $\mathrm{K}$ & $4.4 \mathrm{mEq} / \mathrm{L}$ \\
\hline $\mathrm{Cl}$ & $96 \mathrm{mEq} / \mathrm{L}$ \\
\hline CRP & $0.03 \mathrm{mg} / \mathrm{dL}$ \\
\hline LDL-Cholesterol* & $168 \mathrm{mg} / \mathrm{dL}$ \\
\hline HDL-Cholesterol & $54 \mathrm{mg} / \mathrm{dL}$ \\
\hline Triglyceride & $138 \mathrm{mg} / \mathrm{dL}$ \\
\hline FBS & $98 \mathrm{mg} / \mathrm{dL}$ \\
\hline HbA1c & $5.2 \%$ \\
\hline \multicolumn{2}{|l|}{ Serology } \\
\hline HBsAg & negative \\
\hline $\mathrm{HCV}-\mathrm{Ab}$ & negative \\
\hline Anti-nuclear Antibody & $<40$ \\
\hline Anti-mitochondrial M2 Antibody & $<6.7 \mathrm{U} / \mathrm{mL}$ \\
\hline $\operatorname{IgG}$ & $1,890 \mathrm{mg} / \mathrm{dL}$ \\
\hline $\operatorname{IgM}$ & $168 \mathrm{mg} / \mathrm{dL}$ \\
\hline $\operatorname{IgA}$ & $250 \mathrm{mg} / \mathrm{dL}$ \\
\hline
\end{tabular}

*These values are outside the normal range.

menstrual cycle had been irregular over the previous 2 years.

Physical examination revealed blood pressure 120/70 $\mathrm{mmHg}$, pulse rate 85 beats/min, temperature $36.4{ }^{\circ} \mathrm{C}$ and oxygen saturation on room air $99 \%$. She was alert and oriented. Her skin turgor was almost normal and she did not have a dry mouth. Her abdomen was obese and soft, with normal bowel sounds, no tenderness and no striae. Electrocardiography and chest X-ray showed no significant abnormalities. Laboratory testing 1 week before admission showed liver dysfunction and dyslipidemia, but no other abnormalities (Table 1). Her abnormal laboratory data were as follows: serum aspartate aminotransferase 49 IU/L (normal range: 10 - 38 IU/L), alanine aminotransferase $57 \mathrm{IU} / \mathrm{L}$ (normal range: 0 - $35 \mathrm{IU} / \mathrm{L}$ ), $\gamma$-glutamyl transpeptidase $73 \mathrm{IU} / \mathrm{L}$ (normal range: 0 - 55 IU/L), alkaline phosphatase 321 IU/L (normal range: 105 $320 \mathrm{IU} / \mathrm{L})$ and low density lipoprotein-cholesterol $168 \mathrm{mg} /$ dL (normal range: 70 - $139 \mathrm{mg} / \mathrm{dL}$ ). Blood gas analysis on room air was normal. Urine analysis was normal, with a spe- 
Table 2. Plasma Hormone Concentrations on the First Postoperative Day

\begin{tabular}{lll}
\hline & Measured Value & Normal Range \\
\hline GH & $1.02 \mathrm{ng} / \mathrm{mL}$ & $0.28-1.64$ \\
PRL & $9.57 \mathrm{ng} / \mathrm{mL}$ & $6.12-30.54$ \\
ACTH & $15.8 \mathrm{pg} / \mathrm{mL}$ & $7.2-63.3$ \\
Cortisol & $20.5 \mathrm{mg} / \mathrm{mL}^{*}$ & $4.0-18.3$ \\
TSH & $1.24 \mathrm{pg} / \mathrm{mL}$ & $0.43-3.78$ \\
Free T3 & $2.4 \mathrm{pg} / \mathrm{mL}$ & $2.1-4.1$ \\
Free T4 & $1.2 \mathrm{ng} / \mathrm{dL}$ & $1.0-1.7$ \\
PRA & $3.5 \mathrm{ng} / \mathrm{mL} / \mathrm{hr}^{*}$ & $0.2-2.7$ \\
Aldosterone & $225 \mathrm{pg} / \mathrm{mL} *$ & $30-159$ \\
\end{tabular}

ACTH, adrenocorticotropic hormone; AVP, arginine vasopressin; $\mathrm{GH}$, growth hormone; PRA, plasma renin activity; PRL, prolactin; TSH, thyroid-stimulating hormone. * These values are outside the normal range.

cific gravity of 1.012. Abdominal ultrasonography showed a normal-sized liver with poorly defined margins and a diffuse increase in echogenicity, consistent with fatty liver. No ascites was observed. It was concluded that her abnormal liver function test results were due to non-alcoholic fatty liver disease, and that general anesthesia was not contraindicated.

During the first $24 \mathrm{~h}$ after hospitalization, her oral water intake was $3,200 \mathrm{~mL}$ and her urine output was $2,520 \mathrm{~mL}$. She did not receive intravenous fluids during that time. On the day after admission, she underwent simple hysterectomy under general anesthesia with no complications. On the day of surgery, she received $3,200 \mathrm{~mL}$ of intravenous fluid and lost $520 \mathrm{~mL}$ of blood, and her urine output was $2,570 \mathrm{~mL}$. No corticosteroids were administered during the perioperative period. No neoplasia was detected in the surgically resected specimen.

The next day after surgery, she received $3,200 \mathrm{~mL}$ of intravenous fluid and her urine output increased dramatically to $7,800 \mathrm{~mL}$. Although oral food or water intake was permitted in the morning on that day, she complained of severe thirst and a compelling urge to drink water. Her plasma sodium concentration was high at $157 \mathrm{mEq} / \mathrm{L}$. Although her urine osmolarity was $<180 \mathrm{mOsm} / \mathrm{kg}$, her plasma osmolarity was high at $322 \mathrm{mOsm} / \mathrm{kg}$. In spite of her hypernatremia, her urinary sodium excretion was only $22 \mathrm{mEq}$ /day. Urine analysis showed a low specific gravity of 1.005 and no sediment. Her serum creatinine concentration was $1.17 \mathrm{mg} / \mathrm{dL}$ and her creatinine clearance rate was $51 \mathrm{~mL} / \mathrm{min}$. Her arterial blood $\mathrm{pH}$ remained normal, her serum potassium concentration was $3.9 \mathrm{mEq} / \mathrm{L}$, and serum calcium concentration was $9.8 \mathrm{mg} / \mathrm{dL}$, indicating that she was unlikely to be in the
Table 3. Results of Vasopressin Test

\begin{tabular}{lll}
\hline & $\begin{array}{l}\text { Plasma } \\
\text { Osmorality* }\end{array}$ & $\begin{array}{l}\text { Urinary } \\
\text { Osmorality* }\end{array}$ \\
\hline $\begin{array}{l}\text { Pre-administration } \\
\text { 2 hour after AVP } \\
\text { Administration }\end{array}$ & 286 & 165 \\
\hline
\end{tabular}

AVP, arginine vasopressin. *Units: mOsm/kg.

polyuric phase of acute tubular necrosis or to be developing secondary nephrogenic diabetes insipidus due to hypokalemia or hypercalcemia. Her basal concentrations of anterior pituitary hormones were largely within normal limits (Table 2). Her elevated plasma concentrations of aldosterone and renin were thought to be a response to volume depletion. However, her plasma arginine vasopressin concentration measured by radioimmunoassay was relatively low (0.9 $\mathrm{pg} / \mathrm{mL}$ ) considering her high plasma osmolarity. Testing for antipituitary, antithyroid and antinuclear antibodies was negative. T1-weighted magnetic resonance imaging of the pituitary gland showed absence of hyperintense signals and no enlargement of the neurohypophysis or thickening of the pituitary stalk (Fig. 1). She underwent a vasopressin test, and her urinary osmolarity increased to $512 \mathrm{mOsm} / \mathrm{kg}$ at $120 \mathrm{~min}$ after administration of 5 units of arginine vasopressin (Table $3)$. She was diagnosed with CDI, and was treated with $10 \mu \mathrm{g}$ of intranasal 1-desamino-8-arginine vasopressin (DDAVP) daily. Over the following week, her serum sodium concentration gradually decreased to $140 \mathrm{mEq} / \mathrm{L}$ and her urine output decreased to $<2,500 \mathrm{~mL} /$ day. According to the Japanese guidelines for definitive diagnosis of CDI, administration of DDAVP was temporarily suspended, she was allowed free oral water intake, and a 5\% hypertonic saline infusion test $(0.05 \mathrm{~mL} / \mathrm{kg} / \mathrm{min}$ for 120 minutes) was performed. Her plasma arginine vasopressin concentration did not increase after the hypertonic saline infusion (Fig. 2), whereas her plasma osmolarity gradually increased. Both the results of the vasopressin test and the hypertonic saline infusion test met the criteria for CDI, but her 24-h urine output on the day of admission $(<3,000 \mathrm{~mL})$ and her urine specific gravity $(>$ 1.010) did not meet the criteria. We therefore made a diagnosis of partial CDI.

Further questioning revealed that the patient had first noticed polyuria and extreme thirst during the last trimester of her second pregnancy. Her water intake had gradually increased from $2,500 \mathrm{~mL} /$ day to $3,500 \mathrm{~mL} /$ day over a few months. During this time she had started to drink large volumes of sweetened carbonated beverages and juice. Over the following 5 years she had gained $50 \mathrm{~kg}$. It was therefore possible that the excessive consumption of these beverages due 
A.

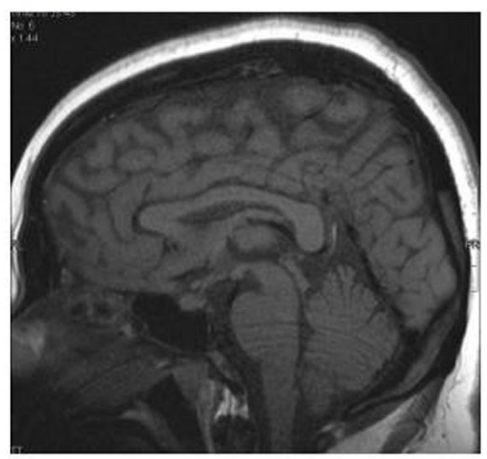

B.

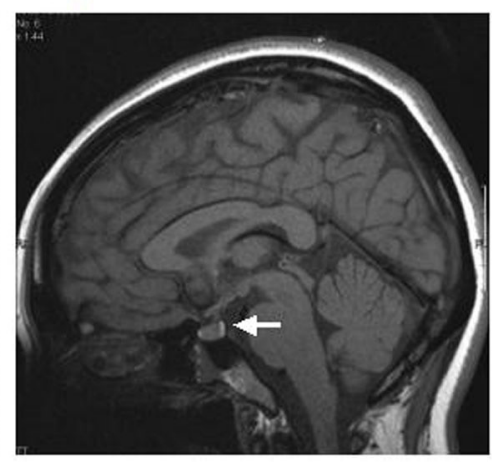

Figure 1. Pituitary T1-weighted magnetic resonance images of our patient (A) and a healthy young woman (B). In the young healthy woman, there is a hyperintense signal in the region of the posterior lobe of the pituitary gland (white arrow); this was absent in our patient. There was no thickening of the pituitary stalk or abnormality of the anterior lobe of the pituitary gland.

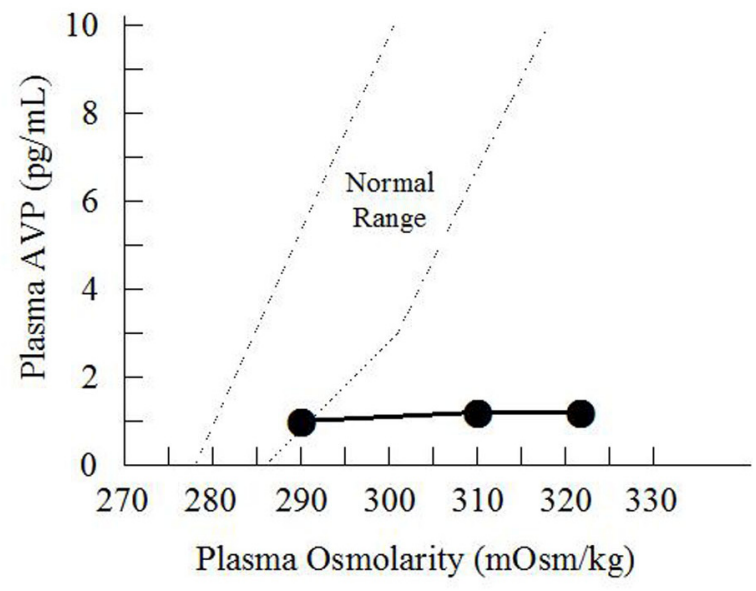

Figure 2. Hypertonic saline infusion test. The patient was given an intravenous infusion of $5 \%$ saline solution at $0.05 \mathrm{~mL} / \mathrm{kg} / \mathrm{min}$ for $120 \mathrm{~min}$. Her arginine vasopressin (AVP) level remained low $(\bullet)$. The dotted lines indicate the normal range of arginine vasopressin concentration according to plasma osmolarity.

to the thirst caused by diabetes insipidus contributed to her obesity. Dietary therapy with caloric restriction initially resulted in a $5 \mathrm{~kg}$ weight loss over 2 months. Her DDAVP was reduced to $5 \mu \mathrm{g} /$ day after 6 months. A year after discharge, she weighed $95 \mathrm{~kg}$.

\section{Discussion}

CDI is a rare condition with an estimated prevalence of 3 per 100,000 persons [6]. We presume that our patient developed diabetes insipidus 6 years before diagnosis, during her second pregnancy. Soul et al [7] classified patients with transient diabetes insipidus during pregnancy into four major subgroups: (1) those with hepatic dysfunction such as acute fatty liver, which suppresses degradation of vasopressinase, resulting in a marked decrease in plasma arginine vasopressin concentration; (2) those with panhypopituitarism as a complication of obstetric shock, including Sheehan's syndrome; (3) those with subclinical neurogenic diabetes insipidus and various degrees of pre-existing vasopressin deficiency; and (4) those with nephrogenic diabetes insipidus with concomitant resistance to arginine vasopressin. Our patient had not experienced severe liver dysfunction or obstetric shock associated with her second pregnancy, and her polyuria and polydipsia persisted after delivery. She also did not have a family history of diabetes insipidus, or significant abnormalities on magnetic resonance imaging. We therefore made a diagnosis of idiopathic CDI.

Undiagnosed CDI often causes a medical emergency due to severe hyperosomolarity and dehydration when fluid intake does not match obligate losses [8]. In the present case, we first noticed polyuria and hypernatremia postoperatively. Limitation of free oral water intake was probably the most significant cause of the intensification of her symptoms. Increased secretion of adrenocorticotropic hormone and corticosteroids induced by surgical stress might also have intensified her symptoms, because adrenocorticotropic hormone suppresses arginine vasopressin secretion [9] and an increased cortisol level causes sodium retention. Laboratory testing revealed a mild increase in plasma corticosteroid concentration, which may have contributed to her increased urine output. The possibility of potent adrenocortical insufficiency should also be considered because of her relatively low serum sodium concentration $(139 \mathrm{mEq} / \mathrm{L})$ and urine 
output $(2,500 \mathrm{~mL} /$ day $)$ during the preoperative period. $\mathrm{Al}$ though no pituitary gland pathology was detected in this case, past studies have reported that lymphocytic infiltration of the neurohypophysis is associated with CDI, and lymphocytic infiltration of the adenohypophysis is associated with hypopituitarism [10, 11]. Lymphocytic adenohypophysitis occurs exclusively in young women during pregnancy [11], and causes preferential impairment of cells secreting adrenocorticotropic hormone and thyroid stimulating hormone [11]. It was previously considered that lymphocytic adenohypophysitis spared the neurohypophysis [12], but a review article reported that some patients with lymphocytic adenohypophysitis develop CDI [13]. Idiopathic adrenalitis may also occur in patients with lymphocytic adenohypophysitis [13]. We therefore suggested corticotropin-releasing hormone and adrenocorticotropic hormone tests, but the patient refused consent. Although she has shown no obvious signs of adrenocortical insufficiency since her discharge, careful follow-up is considered important.

In management of the present case, the most significant problem was that we did not diagnose CDI at the time of first contact. The main reason for this was the lack of a detailed medical history. Patients with CDI may not notice the onset of diabetes insipidus until urine output exceeds $4,000 \mathrm{~mL} /$ day [8]. Patients with an adequate thirst mechanism and free access to water may not develop dehydration or hypernatremia $[5,14]$. However, the polydipsia and polyuria associated with CDI may be so disruptive to daily activities and sleep that patients seek medical attention [5]. Our patient had experienced interruption of sleep several times per night due to her polyuria for 6 years. The frequency of nocturnal awakening helps to determine the optimal DDAVP dose [5]. It is therefore important to obtain a careful history of sleep disturbances when evaluating patients with polyuria of unknown origin. It is also important to discriminate between solute diuresis and water diuresis [15]. For a rapid diagnosis of CDI, both elevated serum osmolarity due to an increased serum sodium concentration and inappropriately low urine osmolarity due to water diuresis are necessary [8]. Measurement of plasma arginine vasopressin concentration confirms the diagnosis, but is not available on an emergency basis [5].

In conclusion, we present a patient with weight gain associated with CDI that had been misdiagnosed as simple obesity. Observation of polyuria after gynecologic surgery provided an opportunity to diagnose CDI, and subsequently treat both her diabetes insipidus and obesity. Clinicians should be alert to the possibility of diabetes insipidus being masked by seemingly unrelated complications.

\section{Acknowledgments}

This work was done at Social Insurance Gunma Chuo General Hospital, Maebashi, Gunma, Japan.

\section{Conflict of Interest}

No conflict of interest.

\section{Grant Support}

No Funding.

\section{References}

1. Makaryus AN, McFarlane SI. Diabetes insipidus: diagnosis and treatment of a complex disease. Cleve Clin J Med. 2006;73(1):65-71.

2. Robertson GL. Diabetes insipidus. Endocrinol Metab Clin North Am. 1995;24(3):549-572.

3. Cagno JM. Diabetes insipidus. Crit Care Nurse. 1989;9(6):86-93.

4. Ghirardello S, Garre ML, Rossi A, Maghnie M. The diagnosis of children with central diabetes insipidus. J Pediatr Endocrinol Metab. 2007;20(3):359-375.

5. Singer I, Oster JR, Fishman LM. The management of diabetes insipidus in adults. Arch Intern Med. 1997;157(12):1293-1301.

6. Saborio P, Tipton GA, Chan JC. Diabetes insipidus. Pediatr Rev. 2000;21(4):122-129; quiz 129.

7. Soule SG, Monson JP, Jacobs HS. Transient diabetes insipidus in pregnancy--a consequence of enhanced placental clearance of arginine vasopressin. Hum Reprod. 1995;10(12):3322-3324.

8. Buonocore CM, Robinson AG. The diagnosis and management of diabetes insipidus during medical emergencies. Endocrinol Metab Clin North Am. 1993;22(2):411423.

9. Raff H. Glucocorticoid inhibition of neurohypophysial vasopressin secretion. Am J Physiol. 1987;252(4 Pt 2):R635-644.

10. Imura H, Nakao K, Shimatsu A, Ogawa Y, Sando T, Fujisawa I, Yamabe H. Lymphocytic infundibuloneurohypophysitis as a cause of central diabetes insipidus. N Engl J Med. 1993;329(10):683-689.

11. Powrie JK, Powell M, Ayers AB, Lowy C, Sonksen PH. Lymphocytic adenohypophysitis: magnetic resonance imaging features of two new cases and a review of the literature. Clin Endocrinol (Oxf). 1995;42(3):315-322.

12. Pestell RG, Best JD, Alford FP. Lymphocytic hypophysitis. The clinical spectrum of the disorder and evidence for an autoimmune pathogenesis. Clin Endocrinol (Oxf). 1990;33(4):457-466.

13. Hashimoto K, Takao T, Makino S. Lymphocytic adenohypophysitis and lymphocytic infundibuloneurohypophysitis. Endocr J. 1997;44(1):1-10.

14. Korzets A, Sachs D, Gremitsky A, Gershkovitz R, Far- 
rage G, Chlibowsky A, Erlich N. Unexplained polyuria and non-obstructive hydronephrosis in a urological department. Nephrol Dial Transplant. 2004;19(9):2410-
2412.

15. Robertson GL. Differential diagnosis of polyuria. Annu Rev Med. 1988;39:425-442. 